Session 2653

\title{
Innovative Design Techniques in a Freshman class
}

\author{
Ravi Pendse Ph.D. , Everett Johnson Ph.D. \\ Department of Electrical Engineering \\ Wichita State University
}

\begin{abstract}
At Wichita State University, we have a three course sequence in the Digital Design area with the first course taken by incoming freshman students. This course entitled "Introduction to Digital Design" is a very popular course among students. The average enrollment each semester is about 60 students. Most of these students go on to take the other two courses in the sequence. In this paper, we will report on different methods used to teach Digital Design to a typical freshman student. The design team concept, which is emphasized throughout the semester, will be presented in this paper. Different innovative ideas used in this class include, use of design teams, peer design team conferences, cost evaluation, and industry interfacing. All of these ideas will be presented in this paper. Comments from students suggest that they find this course to be fun and challenging. What makes this course fun and challenging? How is the design team concept working? Some possible answers to these questions are also presented.
\end{abstract}

\section{Introduction}

An informal poll of Engineering educators indicates that it is a great idea to teach design techniques as early as possible to Engineering students. In the Electrical Engineering(EE) Department at Wichita State University, we have a freshman level course in Digital Design. This is a required course for EE majors. Different techniques are used in this course to emphasize working environment of the "real world." In this paper, the course structure and ideas used in this freshman level class are discussed.

\section{About the course}

Course goal: On the first day of the class, the goal of this course is mentioned and emphasized. The goal is "By the end of the semester, a student will be able to design, simulate, build, and cost a simple (not trivial) digital system." To further emphasize the type of digital system designed, several examples are discussed. Some of which are, a vending machine controller, traffic light intersection controller, and other control circuits. Following the discussion of the examples, the "goal" is further elaborated to emphasize that design does not just mean paper design. What the students will learn will include different phases of design, just as in the "real world."

Course Pre-requisites and hours: This is a freshman level course and has a pre-requisite of basic algebra which most of our incoming students have already taken. This is a one semester (16 weeks) four-hour course which includes three hours of lectures and one hour of lab work. 
Homework and Teamwork: Since most Engineering students are expected to work in teams after they graduate, team work is emphasized from the beginning of the semester. Students are encouraged to work on homework (HW) in teams. The maximum size of a team for HW is two students. For the first several homework assignments, the students are encouraged to work with different people in the class. This allows them to find out with whom they can work. This generally eliminates any personnel problems in a team early in the semester. Once a team is formed, the members of the team are required to sit together in the class. This approach, in our opinion, has many advantages. It allows the students to get to know many other people in the class. In a freshman level class, having a peer group to consult builds confidence. When problems are assigned in the class, each team works on them. When answering questions, a team feels less intimidated than an individual. This has resulted in a more interactive classroom. Last, but not the least, this has resulted in fewer papers to grade.

Design Assignment: The design problems assigned are divided into two groups. Simple design problems are assigned as in-class problems. The number of simple design assignments depends upon the class time available. Two challenging design projects are assigned to be worked outside the class. For the in-class design problems, a fixed time is given. The design solution of the first team to finish is discussed in the class. Constructive suggestions, if needed, are invited from the class. More polished and innovative design ideas have resulted from this approach. For more involved design projects, students are typically given about three weeks to finish. From the word statement of the problem, each team comes up with a paper design. Using the paper design and CAD tools[1], all teams are required to simulate their design. Once they have a working design, each team is required to build a prototype and make it work. A formal written report is required from each team on these projects.

Informal Industry Liaison: One advantage we have at Wichita State University is our nontraditional student base. A good number of our students have co-op or part-time jobs. A great percentage of our students work full-time and attend school part-time. The entire class is encouraged to find students who are working for different companies, either in their class or through the IEEE student group, and use them as a resource for completing their design projects. Using this valuable resource, a student is better able to prepare a professional report for the design projects.

Economics 101: While this course by no means claims to teach students everything they need to know about economics, it does give them some common sense ideas. One simple idea that is emphasized is "Can you sell what you have designed." For a design project, the design teams are required to evaluate the cost of the components used by utilizing library and internet resources. Using the informal industry resource, they compute labor and other costs. Using appropriate profit margin information, the selling cost of a design is determined. This gives them some appreciation of the necessity for low-cost efficient design.

Peer Design Conferences: Three classes are reserved for this activity. Students are divided into groups. Each group has between 4 to 6 students. A handout containing several design problems is distributed to the class. These problems are meant for discussion only. Some of the problems 
include: design of a device to help physically disabled people confined to a wheel chair, do pushups; design of a tachometer for a bike; and so on. The students spend a fixed amount of time brain storming and then make verbal presentation to the whole class. Different groups are asked to present their ideas. These ideas are modified with the feedback from the class. The student feedback indicates that they find this activity challenging and enjoy seeing different ideas from different groups. It also gives students an opportunity to make short presentation. While not every person gets a chance to speak in a group, most do.

Lab Work: The lab allows students to build and test prototypes for different designs throughout the semester. The students are assigned 11 to 14 different labs. For each lab, they follow the same design approach of word statement to prototype. The labs are performed in team. The size of the team is two students. The students are not required to submit[2] extensive lab reports. It is our opinion that labs are for making circuits work. Requiring students to write extensive lab reports gets in the way of having fun in the lab. The writing skills of the students are tested in the design project reports.

Ethics 101: The College of Engineering offers a separate ethics class. If a student is expected to learn real world design, then we need to teach them some responsibility that goes with it. Concepts such as proprietary design (belongs to a design team), importance of time commitment (deadlines), and proper reporting of faulty components and equipment (Lab) are emphasized.

\section{Course Content}

As mentioned earlier, this is an introductory level digital design course. The course includes both the combinational circuit design and sequential circuit design. Approximately $45 \%$ of the semester is spent teaching combinational circuit design techniques. The topics include number system, boolean algebra, and minimization using K-map. Two-level circuit design, using different types of gates, is also covered. Some MSI components like multiplexers, adders, and decoders are also covered. Both design and application of these devices is emphasized. The first design project is exclusively based on this material.

The second part of the semester is used to teach sequential circuit design. An introduction to differences between sequential and combinational circuit design is given. The four basic flip flops are covered. Several design examples are done in the class to explain the concept of a state diagram. Some of the design examples include a sequence detector, different type of counters, and shift registers. The second design project covers some of these concepts.

The first two weeks of the lab are used to teach CAD tools and basic internet concepts. For the rest of the semester, lab design assignments parallel the class. This allows students to simulate and test what they have designed in the class. It has been our experience that a student truly enjoys giving life to their paper design. 


\section{Future Plans}

Based on student feedback and retention rates (about $95 \%$ go on to take the next course in the sequence), we find this approach to be very successful. The industry liaison is very popular. We are considering making it a formal liaison by recruiting volunteer engineers from the local industry. As the typical class size is about 60 students, the challenge is to find enough number of volunteer engineers. Perhaps the local chapter of IEEE professional section may give us some volunteers. We will, of course, report on this and any other changes in future conferences.

\section{Conclusions}

It is never too early to teach design. We have been quite successful at WSU in teaching design techniques to our students. A typical student in this class not only learns how to do a paper design but also knows that the design has to sell. The design process takes a student through different phases of "real world." The "team" approach is appreciated by the students. The retention rates show that this approach has been quite successful.

\section{References}

[1] R. Pendse and E. Johnson, "Big Bang Small Bucks: Effective Use of Low-Cost CAD Packages," Frontiers in Education Conference, Salt Lake City, Utah, November 1996.

[2] R. Pendse, "Effective Laboratory Teaching-- What Works for Me," ASEE Midwest section conference, Wichita, Kansas, March 1995.

\section{Biographical Information}

RAVI PENDSE is an assistant professor in Electrical Engineering Department at Wichita State University. His research interests include Computer Architecture, Rehabilitation Engineering, and Digital Design.

EVERETT JOHNSON is Chairman of the Electrical Engineering Department at Wichita State University. His research interests include Computer Architecture and Digital design. 